\title{
"Programming" an Entrepreneur
}

\section{Elona Garo, PhD Cand.}

Career and Management Consultant

\section{Vasilika Kume, Prof.}

School of Economics, UT, Albania

Suada Basho

Economics and Law Major, UNYT, UT, Albania

\section{Doi:10.5901/ajis.2015.v4n1s1p45}

\section{Abstract}

During last decades new education practices has been developed in Albania targeting university students. Many programs are offered to foster entrepreneurship, such as business plan competitions, incubator centers, and related education programs. Students at the senior level are the one to found companies and innovate businesses so they have been targeted. The belief is that this effort will result on self-employment, effecting economic growth and employment opportunities in the country. While implementing new initiatives, policy makers are not clear on how effective they are. Many studies are undertaken on entrepreneurial intent among students and the influence of education. The empirical evidence is tackling the challenging question addressed worldwide: Are educators "the programmers" of self-employment? The conclusion drawn from the review of the research evidence shows that entrepreneurship education as well as other entrepreneurship activities impacts positively the intention of students in such matter. Inspired by the positive results, further empirical study in the area of entrepreneurship intention will be conducted in Albania.

Keywords: entrepreneurship intention, entrepreneurship education, self-employed, Albania.

\section{Introduction}

On the last two decades the promotion of entrepreneurship has emerged in the developing countries. This issue has become a highest priority for the public institutions and particularly universities. Courses are implemented in university and high schools. Outside education system there are programs initiated by donors and nonprofit organization. Recently, in the time of economic crises and highest rate of unemployment, entrepreneurial activities are becoming important for tackling all challenges. The public institutions with long experience in education as well as successful private institutions in Albania are promoting entrepreneurship activities. Many success stories are reported from these institutions where a considerable number of companies are founded by alumni and faculty.

The observation over seven years experience, leading the career center at the University of New York, Tirana showed that students at bachelor level often see the founding of a company as an attractive alternative. The preferences and behaviors of students are influenced by a number of personal, social and economical conditions. Reasons such as the dream to be rich in a short period of time, the opportunity to freely make decisions, the desire to innovate and change the world consist to influence the decision to become entrepreneurs. On the other hand, fewer opportunities in the market, higher unemployment rate, low wages, lack of competition, and poor career development influence entrepreneurial intention to many others. Due to the recent economic crises, the social and economic conditions such as cost cutting, downsizing, and restructuring are very relevant. Important issues such as security in the work place, stability and loyalty are far from the discussion.

Meanwhile technology plays a tremendous role on the creation of start-ups with low cost and innovative solutions. The role models like Mark Zuckerberg, inspire young people not only for financial success, but also for the impact on the life of people in a short period of time. "Zuckerberg wired together a twelfth of humanity into a single network, thereby creating a social entity almost twice as large as the U.S. If Facebook were a country it would be the third largest, behind only China and India. It started out as a lark, a diversion, but it has turned into something real, something that has 
changed the way human beings relate to one another on a species-wide scale. We are now running our social lives through a for-profit network that, on paper at least, has made Zuckerberg a billionaire six times over" (Person of the Year, Time 2010).

While many researches are undertaken on the determinants of entrepreneurship, few are focused on entrepreneurial intent among students and the influence of education in different cultural contexts. In Albania this field is almost untouched. Still researchers are facing the classic question "traits or conditions?" drive students towards selfemployment. For policy makers the findings would be very significant. If the related conditions are the key factors, a change in this direction should have an effect on the entrepreneurial intent. If this is a case, policy makers in legislative and executive bodies as well as in the education institutions would try to improve conditions through tackling the education curricula, the legal infrastructure and will offer financial support to promote young entrepreneurs. This paper attempts to review the research findings and tackle the following question: Are specific university programs "programmers" of entrepreneurship intentions among university students? The findings of this paper support the idea that the positive influence exist. Are thus education, experience, attitude and social norms actually programming the entrepreneurial intent?

\section{Objectives}

The purpose of this paper is to examine the impact of the education programs on entrepreneurship intention serving as "programmers" of new ventures. The key objective of this paper is to review the entrepreneurship education through the lens of entrepreneurial intention. First is to understand the intention models and to review the entrepreneurship programs and they specific roles in the matter. Later is finding evidence on the positive influence of entrepreneurship education on students' entrepreneurship intention in Albania.

\section{Research Questions}

1. Does entrepreneurship education have an impact on entrepreneurial intention?

2. Does previous entrepreneurship experience increase students' intention to become entrepreneurs?

3. Does students' attitude toward entrepreneurship effect the intention to be involved in such activities?

4. Does the Albanian society value positively entrepreneurship activities and does the culture effect students' entrepreneurship intention?

\section{Literature Review}

Over the years many studies are conducted, using very different methodologies. One of the strongest perspective supported by Aizen showed that the intention to carry out a given behavior will depend on the person's attitudes towards that behavior (Ajzen 1991).

Two important contributions of the intention models have influenced the research in the field. Firstly, Shapero and Sokol's theory (1982) of the "entrepreneurial event" and secondly the theory of "planned behavior" (Ajzen 1991).

The theory of the entrepreneurial event is focused on contextual factors that influence an individual perception on creating a venture. The perception are: perceived desirability-the attraction to become an entrepreneur and perceived feasibility-the ability to carry out the behavior towards venture creation (Figure 1, see Appendix).

On the other hand Aizen created the planned behavior theory, which explains a relationship that exist between the intention for a given behavior and the performance. This concept is very similar to self efficacy-the perception of how easy or difficult is the fulfillment of the behavior of interest (Ajzen 1991). There are some elements part of the model: attitude towards behavior, subjective norms and perceived control (Figure 2, see Appendix). Attitude is the degree of positive or negative valuation of the behavior; subjective norms is the social pressure to carry it or not, and the perceived control help to understand how feasible is a person to carry the behavior.

Other authors have contributed through adding other elements to the model mentioning here the presence of role models (Scherer et al., 1991) or a greater knowledge of the entrepreneurial environment (Linnan 2004).

Further studies are undertaken to understand the role of education. While the first entrepreneurship course was offered at Harvard University in the year 1947, when Professor Myles Mace (MBA 1938) first offered a course to returning World War II veterans titled, Management of Small Enterprises. Fifty years later, entrepreneurship was a vital component of the MBA Program (Harvard Business School). From that first class in 1947, an American infrastructure has emerged 
consisting of more than 2,200 courses at over 1,600 schools, 277 endowed positions, 44 English-language refereed academic journals and over 100 centers (Katz, 2003). Since the first attempts numerous courses and teaching programs have occurred in United States and Europe.

Various studies have been conducted to understand if Entrepreneurship Teaching Programs (ETPs) and relevant activities have an influence on the entrepreneurial intention. For example, a study by Kolvereid and Moen (1997) has shown that students with a major in entrepreneurship have a higher intention to engage as entrepreneurs and are likely to initiate business. Noel (2001) attempted a survey on three groups of individuals from different education backgrounds (business, entrepreneurship and the third group from various different schools). The study showed a difference in their career. According to Noel the graduates from entrepreneurship schools launched a greater number of business than the ones from two other groups. Similarly, Varela and Jimenez (2001) study has shown that there is a correlation between a university's investment in the promotion of entrepreneurship and the percentage of students becoming entrepreneurs.

A study conducted by Franke and Luthje showed that the academic tradition of entrepreneurship in Germanspeaking countries is very short. Until recently, fostering innovation and new product development through entrepreneurship has not been regarded a primary task of universities. Through comparing entrepreneurial intention of students at two German-speaking universities (Vienna University of Economics and Business Administration and the University of Munich) and students of Massachusetts Institute of Technology (MIT). Researchers found very distinct patterns of entrepreneurial spirit in these universities: lower level in German-speaking universities might be attributed to less distinctive entrepreneurship education (Franke and Luthje, 2004).

The study by Autio, Keeley, Klofsten, \& Ulfstedt, (1997) through investigating entrepreneurial intention of university students in various cultural contexts showed clearly that the university environment affects the entrepreneurial confidence of university students. The educational programs at universities effected deeply knowledge about entrepreneurship. Similarly, Tkachev and Kolvereid (1999) on their findings reassured that entrepreneurship education and training influence students' entrepreneurship intentions.

Empirical evidence of a study that enrolled participants from the Young Achievement Australia enterprise program reported that after finishing the program significantly higher perception of both desirability and feasibility to become entrepreneurs were evident (Peterman \& Kennedy, 2003).

Researchers Souitaris et al. based on the theory of planned behavior tested the effect of entrepreneurship programs on the entrepreneurial attitudes and intentions of science and engineering students. The results showed that the programs influence positively students' attitudes and the overall entrepreneurial intention. The findings contributed further to the theories of planned behavior (Ajzen 1991) and to the practice of teaching entrepreneurship (Souitaris et al, 2007).

Another impressing evidence showed that approximately 4,000 MIT-related companies exist today, with total employment exceeding 1.1 million people and annual sales of $\$ 232$ billion. "If the companies founded by MIT graduates and faculty formed an independent nation, the revenues produced by the companies would make that nation the 24th largest economy in the world," (Ayers 1997). Similar success stories are reported in different European regions where the entrepreneurial universities showing that the impact is widespread.

A study conducted in Asia examined the level and determinants of interest in entrepreneurship among university undergraduate students in Singapore based on a large sample survey conducted in 1998. Three background factors such as gender, family experience with business and educational level, are found to affect entrepreneurial interests, but not family income status, ethnicity and citizenship. The empirical findings strongly suggested the need to provide students in engineering and science with educational programs that convey business knowledge (Wang and Wong).

The research is not limited to only developed countries as mentioned in the cases above. In a study conducted in Iran, where 320 students and 6 universities were involved, the entrepreneurship education programs have shown a significant impact on the students' entrepreneurial intentions. The findings strongly suggested that participation in education programs positively influenced students' entrepreneurial intentions and perceived behavioural control conforming that universities can shape and foster entrepreneurial intentions.

\section{Methodology and Study Results}

The key objective of this study is to examine the students' entrepreneurship intention through analyzing the phenomena among undergraduates. The instrument used is "Entrepreneurial Intention Questionnaire" (Linnan at al, 2006). This questionnaire is used in a series of work by Linnan and Chen (2009) in different countries and culture contents. It is an instrument created to study entrepreneurial intention of young people through collecting data related with entrepreneurial 
activity, social norms, education and experience, abilities, knowledge, entrepreneurial objectives, and creation of a new venture. All factors are measured using Likert scale from 1-7.

The data was gathered by conducting a survey at the University of New York, Tirana, being the oldest and one of the most successful private university in the country. The total number of observations is 64 . All of the respondents were undergraduates, majored in business or related studies. Specifically, 31\% were studying finance, $22 \%$ business administration, $13 \%$ marketing, whereas the others were studying accounting, economics, and management. Students were selected to be mostly in the last year of studies because they are the first to have the necessity of making career decisions.

Out of all respondents $66 \%(n=42)$ were female and $94 \%(n=60)$ were aged between $21-24$. It is observed that as for the place of birth there is a variation among students, where $37 \%(n=24)$ were from Tirana (capital city), 16\% $(n=10)$ were from Durres, $9 \%(n=6)$ from Fier, and the rest were coming from cities such as Elbasan, Pogradec, Vlora, and Saranda (see Graph 1 and Graph 2, Gender and Age Distribution).

The curricula used in business related majors brings students closed to knowledge and skills on entrepreneurship. Students were involved in internship programs, they participated frequently in workshops and study visits, where they were exposed to information given by professional guest speakers and prominent business leaders. Part time professors working in key positions in the Albanian market through teaching have shared valuable practical lessons to students. The study was focused to observe this phenomena of knowledge sharing among students (see Graph 3, Level of knowledge about business associations, support bodies and other measures that support firm creation).

Regarding knowledge about entrepreneurship that education offers to students we focused our study on the aspects described in Graph 3. The findings are summarized in the Table 1. The valuation coming from respondents for all these measures that support firm creation as it is shown in the Table 1, highlight the idea that the University is healthy on knowledge sharing.

The results of the questionnaires show that the importance of career opportunities to choose their major (degree) is $93 \%$, meaning this reason is valued from University students as highly important. In addition, they have been asked to what extent it is possible to offer entrepreneurship education courses which develop aspects related to entrepreneurship. Their valuation is shown on Table 2, for each aspect that they have been asked.

The data of Table 2 show that students value the University's role into entrepreneurship education to be quite good. Through its programs students have been challenged to know the entrepreneurial environment, to recognize and respect entrepreneurs' role in society, to have skills on entrepreneurship, and shape the intention to be an entrepreneur.

The findings of the questionnaire show that $62 \%$ of respondents $(n=40)$ had working experience and specifically for $30 \%$ of them the working experience was a self-employment one. The observations positively answer to the question of knowing on entrepreneur amount to be 58 , which means $90 \%$ of participants have been close to an entrepreneur or/and entrepreneurial activities. Students that have been exposed to such experiences is believed are influenced by them.

The level of interest in entrepreneurship is valued from $n=60$ respondents, which means that $94 \%$ of students answer positively into having the entrepreneurship intention. Out of them $81 \%$ answered to be determined into starting a firm in the future. To the Likert scale from 1-7 students valued 5.1 their professional goal to be, becoming an entrepreneur. In general participants show that they are able and they have enough skills to undertake entrepreneurial activities. The result of the study shows that the participants believed that they are $54 \%$ capable to undertake such activities now. This result included their attitude towards creative skills, problem solving, communication and leadership skill, and networking needed to become a successful entrepreneur (see Table 3 and 4).

Overall the perception coming from this study is that students questioned for the purpose of measuring the entrepreneurial intention is positive towards being able and willing to become an entrepreneur.

The Albanian society gives value to the entrepreneurial activities according to this sample. This point is support from the data that shows that the social valuation of entrepreneurial activities from family according to the respondents is $76 \%$, from friends is $64 \%$, and among colleagues this social valuation amounts $66 \%$. Focusing on family, these students part of the survey come from families with entrepreneurial experiences. Regarding their answers $60 \%$ of their fathers were self-employed compare to $52.5 \%$ of their mothers (see Graph 3 ). As a result the findings coming from this sample answered positively the research questions addressed in this study.

\section{Conclusion}

The review of empiric evidence in this paper retrieved from studies undertaken in different cultures and in Albania showed a significant relationship between entrepreneurial programs and the propensity of fostering entrepreneurship. Knowing 
that Entrepreneurship Training Programs can change entrepreneurial intention is fascinating if one considers the economic prosperity mentioned by various authors. The findings included in this paper are very optimistic showing the positive influence towards entrepreneurship. Besides practical reasons, intentions have been identified as being the best predictors of planned behavior. Therefore, entrepreneurship can be declared as a type of planned behavior which can be analyzed with the help of intention models. Additionally, understanding the antecedents of intentions implies understanding the behavior.

Recently in Albania studies are undertaken on entrepreneurial intent among students. The empirical evidence from the study undertaken by Kume et al., "Entrepreneurial Characteristics amongst University Students in Albania" showed that among other factors, entrepreneurship education impacts positively the entrepreneurial intention of students.

Intention models seem to be a solid starting point for the analysis of entrepreneurship. In particular, the best solution is the integrated Ajzen's (1991) and Shapero \& Sokol's (1982) theories into an entrepreneurial intention model.

For the case of Albania the research findings show a positive correlation between entrepreneurial programs and entrepreneurial intent as it was expected. Besides education, experience, attitude and social norms are also observed and the results support the expectation that these consist to shape entrepreneurial intent, too. As a result "programming" an entrepreneur is a possible process. The selected sample coming from University of New York, Tirana highlights that the entrepreneurial intention these students have is a result of family background (involved in the entrepreneurial activities) and a fully entrepreneurial education.

The findings of this paper can serve as a best practice for higher education institutions and policy makers in the country. Firstly, as long as the influence of education programs is proved from evidence in this specific case, then university curricula overall should be revised in order to solve the issue of preparing and supporting possible new entrepreneurs. Secondly, education institutions should pay attention to expose young students to knowledge about possibilities and resources that would help them build an enterprise. Finally, findings about the situation of entrepreneurs and entrepreneurship in Albania should be source for public institutions to orientate their policies towards being supportive on this matter.

The positive correlation between entrepreneurial programs and entrepreneurial intent in the case of University of New York, Tirana, and the great importance for the country are the inspiration for a natural extension of the work, the use of intention models to test results in the Albanian context.

\section{Limitation of the Study}

The authors accept that the observations are undertaken in a limited setting, a small private university in the country. As a result, the limitation in the sample size is obvious. The access to a larger size of observation in this institution is not a case considering that the sample fully represents the target group in focus. This case shows the positive effect of education into programming entrepreneurs, but definitely it does not represent the case of Albania. Answering this question will be inspiration for further scientific studies. Future research must include students from other universities, public and private, aiming to cover the whole country.

The survey is relied on self-reported data as a result taking into account what students said on questionnaires creates the base of information. Potential sources of bias could be noted in this case including students' memory- the ability to remember or not remember experiences that occurred in the past. Another bias is the attribution of entrepreneurial intention to only some factors without valuing others. Exaggeration on responses as a result of personal family entrepreneurial experiences- most of respondents being the second generation of entrepreneurs in the countrymight have resulted in a more significant outcome (positive entrepreneurial intention) than suggested from other studies undertaken recently in the public university in Tirana (Kume et al., 2013).

While many researches are undertaken worldwide, Albania missed this opportunity. Limited number of research are noted in the last years in this area of study. The need for further research in this field is necessary.

\section{References}

Ajzen, I., (1991)"The theory of planned behavior", Organizational Behavior and Human Decision Processes, vol. 50, p. $179-211$. Ajzen, I., (1991) "Nature and operation of attitudes", Annual Review of Psychology, vol. 52, p. 27-58.

Autio, E., Keeley, R.H., Klofsten, M. \& Ulfstedt, T. (1997). Entrepreneurial Intent Among Students: Testing an Intent Model in Asia, Scandinavia and USA, Frontiers of Entrepreneurship Research, Babson Conference Proceedings, www.babson.edu/entrep/fer Ayers, W.M. (1997) MIT: The impact of innovation, BankBoston Economics Department Special Report, Boston. 
Cruikshank J., (2002), "A Half-Century of Teaching Entrepreneurship", Entrepreneurship, Harvard Business School, www.hbs.edu/ entrepreneurship/newbusiness/history.html.

Franke N. and Luthje Ch., (2004), Entrepreneurial Intentions of Business Students-A Benchmarking Study, International Journal of Innovation and Technology Management, Volume 01, Issue 03.

Grossman P., (2010) "Person of the Year", Time Magazine.

Karimi S., (2012), The Role of Entrepreneurship Education in Developing Students' Entrepreneurial Intentions, Social Science Research Network

Katz J., (2003), "The Chronology and Intellectual trajectory of American Entrepreneurship Education 1876-1999", Journal of Business Venture 18, p. 284.

Kolvereid, L. \& Moen, O. (1997). Entrepreneurship among business graduates: Does a major in entrepreneurship make a difference? Journal of European Industrial Training, 21 (4), p.154.

Kume, A., Kume V., \& Shahini B., Entrepreneurial Characteristics amongst University Students in Albania, European Scientific Journal, ISS: 1857-7881, 2013

Linan F. (2004), Intention Based Models of Entrepreneurship Education, IntEnt2004 Conference, Naples, Italy.

Noel, T.W. (2001). Effects of entrepreneurial education on student to open a business. Frontiers of Entrepreneurship Research, Babson, Conference Proceedings. Babson College, www.babson.edu/entrep/fer.

Peterman N. \& Kennedy J., (2003), Enterprise Education: Influencing Students' Perceptions of Entrepreneurship, Entrepreneurship Theory and Practice, Volume 28, p. 129-144

Tkachev, A. and Kolvereid, L. (1999), "Self-employment intentions among Russian students", Entrepreneurship and Regional Development, 11, p. 269-280.

Souitaris V., Zerbinati S. Al-Laham A. (2007), Do Entrepreneurship Programmers Raise Entrepreneurial Intention of Science and Engineering Students? The Effect of Learning, Inspiration and Resources, Journal of Business Venturing 22 (2007) 566-591, www.sciencedirect.com

Scherer, R.F., (1991) Brodzinsky, J.D. \& Wiebe, F.A., "Examining the relationship between personality and entrepreneurial career preference", Entrepreneurship and Regional Development, vol. 3, p. 195-206.

Varela R., Jimenez J.E., (2001), "The effect of entrepreneurship education in the universities of Cali", Frontiers of Entrepreneurship Research, Babson Conference Proceedings, www.babson.edu/entrep/fer.

Wang C. and Wong P., (2004), Entrepreneurial Interest of University Students in Singapore, Technovation, Volume 24, Issue 2, p. 163172.

\section{Appendix}

Table 1. Level of knowledge about business associations, support bodies and other measures that support firm creation

$\begin{array}{ccccccc} & \text { Business } & \text { Support } & \text { Specific trainings for young } & \text { Loans in specially } & \text { Technical aid to start } & \text { Business } \\ \text { entrepreneurs } & \text { favorable terms } & \text { the business } & \text { centers } \\ \text { Mean } & 52.3 \% & 53.4 \% & 53.9 \% & 45 \% & 51.25 \% & 55.06 \% \\ \text { Mean } & 4.34 & 4.47 & 4.43 & 3.9 & 4.28 & 4.53\end{array}$

Table 2. Entrepreneurship education

Knowledge about the
entrepreneurial
environment
$68.1 \%$
Mean $\quad 5.28$

The preference to be an entrepreneur

$62.8 \%$

5.03

The necessary
abilities to be an
entrepreneur
$56 \%$
4.5

The intention to be an entrepreneur

$75.5 \%$

5.68

Table 3. Measuring entrepreneurial intention

I'm ready to make anything to be an entrepreneur My professional goal is becoming an entrepreneur I will make every effort to start and run my own business I'm determined to create a firm in the future I have very seriously thought in starting a firm I've got the firm intention to start a firm some day

\begin{tabular}{cc}
\multicolumn{2}{c}{ Mean } \\
$53 \%$ & 4.28 \\
$63.6 \%$ & 5.1 \\
$73 \%$ & 5.5 \\
$81.2 \%$ & 5.84 \\
$75.8 \%$ & 5.65 \\
$77.9 \%$ & 5.62
\end{tabular}


Table 4. Entrepreneurial capacity

Respondents' agreement with the following statements:

\begin{tabular}{cc}
\multicolumn{2}{c}{ Mean } \\
$45.5 \%$ & 4 \\
$44 \%$ & 3.87 \\
$56.4 \%$ & 4.6 \\
$48.6 \%$ & 4.1 \\
$54.5 \%$ & 4.5 \\
$63.75 \%$ & 5.03
\end{tabular}

Start a firm and keep it working would be easy for me

I'm prepared to start a viable firm

I can control the creation process of a new firm

I know the necessary practical details to start a new firm

I know how to develop an entrepreneurial project

If I tried to start a firm, I would have a high probability of succeeding

Graph 2. Age distribution

Graph 1. Gender distribution

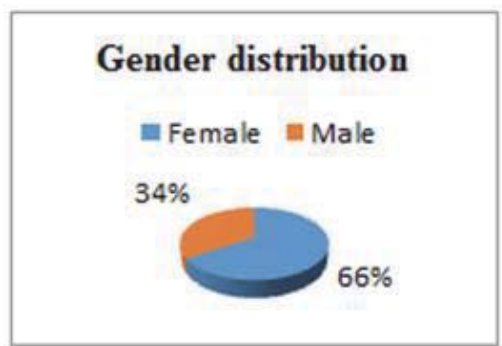

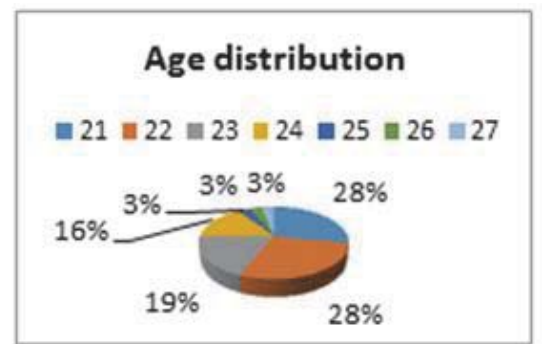

Graph 3. Level of knowledge about business associations, support bodies and other measures that support firm creation
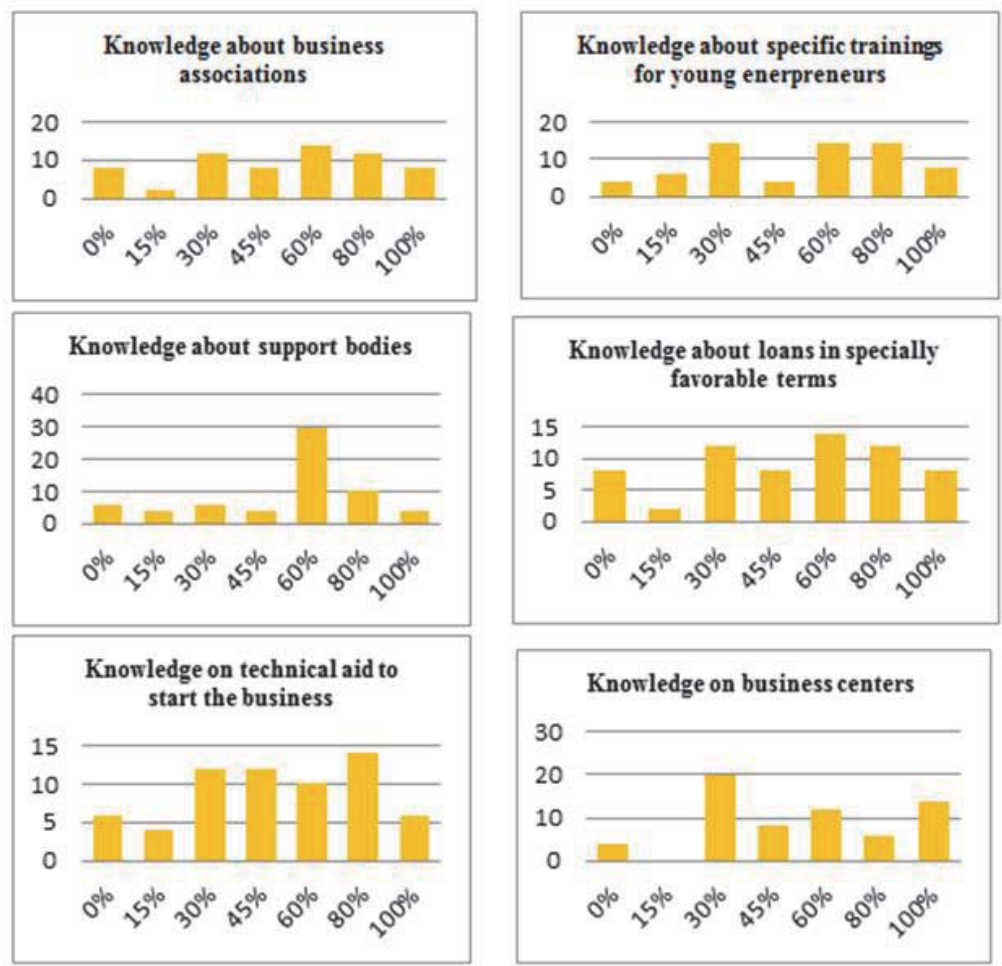
Graph 4. Social valuation of entrepreneurial activity

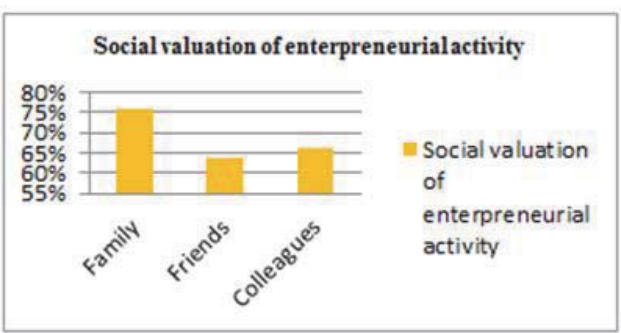

Appendix

Figure 1. Shapero's Model of Entrepreneurial Intentions (1982)

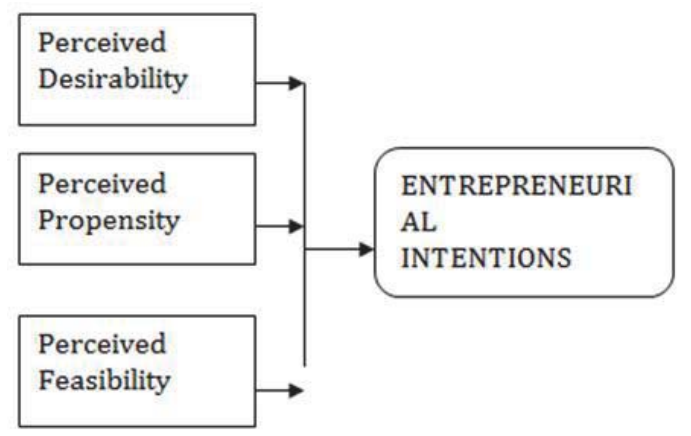

Source: Van Auken, Fry and Stephens (2006).

Figure 2. Theory of Planned Behavior, Ajzen (1991)

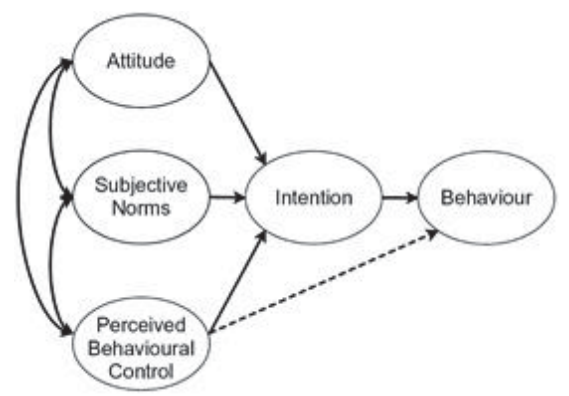

Source: Adopted by Ajzen (1991) 